\title{
Clinical Practice Guideline for Care in the Last Days of Life
}

\section{Jinyoung Shin, M.D., Yoon Jung Chang, M.D.*, So-Jung Park, M.D.*, Jin Young Choi, Ph.D.*, Sun-Hyun Kim, M.D. ${ }^{\dagger}$, Youn Seon Choi, M.D. ${ }^{\dagger}$, Nam Hee Kim, M.D. ${ }^{\S}$, Ho-Kee Yum, M.D. $"$, Eun Mi Nam, M.D. ", Myung Hee Park, R.N.**, Nayeon Moon, M.D. ${ }^{\dagger \dagger}$, Jee Youn Moon, M.D. ${ }^{\ddagger \neq}$, Hee-Taik Kang, M.D. ${ }^{\S}$, Jung Hun Kang, M.D. II ", Jae-Min Park, M.D. "19", Chung-Woo Lee, M.D.***, Seon-Young Kim, M.D. ${ }^{\dagger+}$, Eun Jeong Lee, R.N. ${ }^{\mp \neq}$, Su-Jin Koh, M.D..$^{888}$, Yonghwan Kim, M.D. "ll ${ }^{\prime \prime}$, Myongjin Agnes Cho, M.D. ${ }^{\text {q1/q }}$, Youhyun Song, M.D.*** and Jae Yong Shim, M.D.****}

Department of Family Medicine, Konkuk University School of Medicine, Seoul, *National Hospice Center,

National Cancer Center, Goyang, ${ }^{\dagger}$ Department of Family Medicine, International St. Mary's Hospital College of Medicine, Catholic Kwandong University, Incheon, ${ }^{\ddagger}$ Department of Family Medicine, Korea University Guro Hospital, Seoul,

${ }^{\S}$ Maumtodac Psychiatric Clinic, Ansan, "Department of Internal Medicine, Seoul Paik Hospital, Inje University, "Department of Internal Medicine, Ewha Womans University College of Medicine, ${ }^{* *}$ Hospice \& Palliative Care Unit, The Catholic University of Korea, Seoul St. Mary's Hospital, ${ }^{\dagger \dagger}$ Department of Family Medicine, VHS Medical Center,

${ }^{\ddagger \ddagger}$ Department of Anesthesiology and Pain Medicine, Seoul National University School of Medicine, Seoul,

$\S \S$ Department of Family Medicine, Chungbuk National University College of Medicine, Cheongju, " Department of Internal Medicine, Gyeongsang National University College of Medicine, Jinju, ${ }^{9191}$ Department of Family Medicine,

Gangnam Severance Hospital, Yonsei University College of Medicine, ${ }^{* * *}$ Department of Family Medicine, Korea University, College of Medicine, Seoul, ${ }^{\dagger+\dagger}$ Department of Psychiatry, Chonnam National University Medical School, Gwangju,

キキキHospice \& Palliative Care Center, Korea University Guro Hospital, Seoul, ${ }^{\S \S}$ Department of Hematology and Oncology, Ulsan University College of Medicine, Ulsan University Hospital, Ulsan, "| | "Department of Family Medicine, Chungbuk National University Hospital, Cheongju, ${ }^{9|9| 9 \mid}$ Department of Internal Medicine, Anyang Sam Hospital, Anyang, ${ }^{* * * *}$ Department of Family Medicine, Severance Hospital, Yonsei University College of Medicine, Seoul, Korea

A clinical practice guideline for patients in the dying process in general wards and their families, developed through an evidence-based process, is presented herein. The purpose of this guideline is to enable a peaceful death based on an understanding of suitable management of patients' physical and mental symptoms, psychological support, appropriate decision-making, family care, and clearly-defined team roles. Although there are limits to the available evidence regarding medical issues in patients facing death, the final recommendations were determined from expert advice and feedback, considering values and preferences related to medical treatment, benefits and harms, and applicability in the real world. This guideline should be applied in a way that takes into account specific health care environments, including the resources of medical staff and differences in the available resources of each institution. This guideline can be used by all medical institutions in South Korea.

Key Words: Terminal care, Symptom assessment, Communication, Decision making, Education
Received April 16, 2020

Revised June 19, 2020

Accepted June 24, 2020

\section{Correspondence to}

Jae Yong Shim

ORCID:

https://orcid.org/0000-0002-9561-9230

E-mail: hope@yuhs.ac

This clinical practice guideline was produced by the Korean Society for Hospice and Palliative Care and the National Cancer Center with support from the Ministry of Health and Welfare National Health Promotion Fund (\#1860540-1). The guideline was evaluated and approved by the Korean Academy of Medical Sciences (March 10, 2020). The full text is available at https://www.guideline.or.kr/guide/ view. php? number $=1108$ \& cate $=$ A. 


\section{INTRODUCTION}

With the implementation of the Act on Hospice and Palliative Care and Decisions on Life-Sustaining Treatment for Patients at the End of Life (law 15542; hereinafter referred to as the Act on Decisions on Life-Sustaining Treatment), general end-of-life care for patients in the dying process is required at every medical institution. Therefore, the Korean Society for Hospice and Palliative Care developed an evidence-based clinical practice guideline for patients in the dying process in general wards and their family members for the first time in South Korea.

In this guideline, patients in the dying process are defined as adult patients whose death is anticipated in a few days or during hospitalization due to cancer, chronic diseases, or acute deterioration of chronic organ failure after an accident, who do not recover despite treatment and do not have a possibility of recovery, who experience rapid deterioration of symptoms, and whose death occurs over a prolonged period due to aging or dementia. The definition is not limited to the definition used in the Act on Decisions on Life-Sustaining Treatment and reflects medical professionals' clinical judgement. The aim of this guideline is to help patients in the dying process and their family members to prepare for death, to manage physical and psychological symptoms in the dying process, and to increase quality of life and improve satisfaction among patients and family members by providing psychological support and adequate decision-making so they can prepare for a peaceful death. A limitation is that research on patients in the dying process is lacking, especially large-scale studies that are well-designed, but this guideline was developed by adapting 14 existing clinical practice guidelines both locally and globally [1-14]. Recommendation levels were determined after balancing values and preferences, the benefits and risks of treatments, and circumstances in South Korea by agreement of a multidisciplinary committee (Supplementary Table 1). This review introduces 28 recommendations, and the full document can be viewed at the clinical practice guideline information center (https://www.guideline.or.kr/guide/view. php? number $=1108 \&$ cate $=$ A).

After explaining to the patient and his or her family members the advantages and disadvantages of providing IV fluids and nutrition and the fact that there are no conclusive results on whether the dying process is shortened if IV fluids and nutrition are not given, the patient's comorbidities, cultural viewpoints, religion, level of consciousness, physical condition, level of thirst, and risk of pulmonary edema should be considered before making a decision. No medication has been proven to improve loss of appetite and cachexia in patients in the dying process.

Recommendation 1. Provision of IV Fluids and Nutrition

\begin{tabular}{lcc}
\hline & Evidence & Recommendation \\
\hline $\begin{array}{l}\text { We recommend that before providing intravenous (IV) fluids and nutrition to patients in the dying process, } \\
\text { benefits and risks should be evaluated in terms of the patient's degree of thirst, whether the patient is } \\
\text { dehydrated, the possibility of oral feeding, the risk of aspiration, cardiovascular function, and comorbidities. }\end{array}$ & B & । \\
\hline
\end{tabular}

Recommendation 2. Dyspnea

\begin{tabular}{lcc}
\hline & Evidence & Recommendation \\
\hline $\begin{array}{l}\text { Medical interventions to identify and assess correctable causes of dyspnea in patients in the dying process } \\
\text { should be considered. When considering medication or invasive treatments, the benefits and harm should be }\end{array}$ & $\mathrm{D}$ & lla \\
evaluated against providers' clinical opinions and patients' care requirements. & \\
\hline
\end{tabular}

Recommendation 3. Non-Pharmacological Treatment of Dyspnea

\begin{tabular}{lcc}
\hline & Evidence & Recommendation \\
\hline $\begin{array}{l}\text { In order to ameliorate dyspnea in patients in the dying process, position changes and other non-pharmacological } \\
\text { treatments such as improvements in the environment and psychological relaxation should be considered. }\end{array}$ & $\mathrm{D}$ & $\|$ a \\
\hline
\end{tabular}


It is important to ease the patient's pain by identifying correctable causes of dyspnea and addressing them through pharmacological or non-pharmacological treatment, while simultaneously easing the concerns of the patient and family members by explaining future treatment plans in order to prevent anxiety-induced exacerbation of dyspnea. During the dying process, a broad range of symptoms related to dyspnea occur, and some patients do not respond to noninvasive treatments such as oxygen and diuretics. The benefits and harms associated with additional bloodwork or imagingbased diagnoses should be considered, and if the treatment under discussion is invasive, careful consideration should be made before conducting a test.

In order to improve dyspnea in patients in the dying process, room air should be circulated by opening windows, and adequate temperature and humidity should be maintained. It is helpful to raise the patient's head and to place an electric fan to direct a weak flow of air towards the patient's face. When the patient is conscious, he or she should be instructed to inhale deeply through the nose and exhale for as long as possible through the mouth with lips contracted.
In patients who have not previously received opioids, $5 \sim 10$ mg of morphine can be administered orally. If oral administration is difficult, $2.5 \sim 5 \mathrm{mg}$ can be given intravenously at 2to 4-hour intervals depending on symptoms. If opioids are already being used for pain control, a $25 \%$ increase of the total daily dose can be considered. If dyspnea abruptly develops, an additional $10 \%$ of the total daily dose can be added. If the effect of opioids is insufficient or symptoms deteriorate due to anxiety, benzodiazepines can also be administered.

The effect of using oxygen for patients in the dying process with dyspnea has not been established. Since some patients experience dyspnea due to anxiety, administering oxygen to every patient with dyspnea should be avoided. However, if the cause of dyspnea is known to be hypoxia or if hypoxia is clinically suspected, oxygen can be considered, and if the symptoms improve, oxygen should be maintained. However, there is no need to check oxygen saturation to assess the presence of hypoxia, and when oxygen saturation is low but no symptoms are present, oxygen is not required.

Medical staff should first understand the cause of respiratory secretions and assess the impacts of respiratory secretions on

Recommendation 4. Pharmacological Treatment of Dyspnea

\begin{tabular}{lcc}
\hline & Evidence & Recommendation \\
\hline $\begin{array}{l}\text { Opioids can be considered to improve dyspnea in patients in the dying process. If their effect is insufficient, and } \\
\text { especially if symptoms deteriorate due to anxiety, benzodiazepines can be added. }\end{array}$ & $\mathrm{B}$ & lla \\
\hline
\end{tabular}

Recommendation 5. Oxygen Administration

\begin{tabular}{lcc}
\hline & Evidence & Recommendation \\
\hline $\begin{array}{l}\text { Oxygen is not conventionally administered to patients in the dying process to improve dyspnea. If the cause of } \\
\text { dyspnea is known to be hypoxia or if hypoxia is clinically suspected, oxygen can be considered. }\end{array}$ & $\mathrm{C}$ & lla \\
\hline
\end{tabular}

Recommendation 6. Management of Respiratory Secretions

\begin{tabular}{|c|c|c|}
\hline & Evidence & Recommendation \\
\hline $\begin{array}{l}\text { The use of suction to remove the respiratory secretions of patients in the dying process can be burdensome for patients } \\
\text { due to irritation from catheters, so the choice of whether to use suction should be determined after evaluating the } \\
\text { benefits and harms in terms of the amount of secretions, the patient's status, and the caregiver's needs. }\end{array}$ & $D$ & Ila \\
\hline
\end{tabular}

Recommendation 7. Pharmacological Treatment of Respiratory Secretion

\begin{tabular}{lccc}
\hline & Evidence & Recommendation \\
\hline Pharmacological treatments to suppress respiratory secretions can be considered for patients in the dying process. & $\mathrm{C}$ & & $\| \mathrm{bb}$ \\
\hline
\end{tabular}


patients and family members. The catheter used in oropharyngeal suction does not reach all of the secretions, so oropharyngeal suction is not very effective and can irritate the patient, making him or her suffer more.

Medications to manage respiratory secretions are not commonly given to patients in the dying process, but if the secretions are causing discomfort, medications (e.g., atropine, glycopyrronium bromide, hyoscine butylbromide/hyoscine hydrobromide, and scopolamine) can be started. Symptoms should be checked every $4 \sim 12$ hours, and side effects such as delirium, anxiety, and excessive drowsiness should be monitored (especially when atropine or hyoscine hydrobromide is used). If any discomfort due to respiratory secretions remains after 12 hours, the medication should be discontinued or switched to another drug. When urine retention, delirium or anxiety, excessive sedation, or discomfort due to dry mouth occurs, the medication should be discontinued or switched to another drug.

Clinicians should investigate whether nausea or vomiting is caused by medication (opioids, digoxin, steroids, antibiotics, anticonvulsants, and cytotoxic agents), radiation treatment, psychological causes, electrolyte imbalance, increased intracranial pressure, severe constipation, ascites, gastric paralysis, or bowel paralysis or obstruction and whether the cause is reversible. Moreover, the timing, duration and frequency, amount, triggering or ameliorating factors, and accompanying symptoms should be evaluated. The degree of dehydration should be assessed based on vital signs and by examining the oral cavity and the abdomen. Possible associations with bowel obstruction or encephalopathy should be investigated through a digital rectal examination and an interview, respectively. The results of the above evaluations should be jointly considered to determine whether an intervention will be given for nausea or vomiting.

It is difficult for patients with severe nausea or vomiting to take medicine orally, so an alternative method of administration should be identified. Glucocorticoids are considered when intracranial pressure increases, an acetylcholinergic antagonist (scopolamine) when the cause is vestibular organ dysfunction, and metoclopramide when gastric paralysis occurs. When nausea or vomiting is caused by bowel obstruction, hyoscine butylbromide is considered first, and if the symptoms do not

Recommendation 8. Evaluation of Nausea or Vomiting

\begin{tabular}{lcc}
\hline & Evidence & Recommendation \\
\hline $\begin{array}{l}\text { We recommend that nausea or vomiting in patients in the dying process should be evaluated comprehensively by assessing } \\
\text { possible causes, related factors, and the degree of nausea or vomiting and by performing a physical examination. }\end{array}$ & $\mathrm{D}$ & । \\
\hline
\end{tabular}

Recommendation 9. Pharmacological Treatment of Nausea or Vomiting

\begin{tabular}{lcc}
\hline & Evidence & Recommendation \\
\hline $\begin{array}{l}\text { Validated pharmacological treatments should be considered based on the cause, related factors, and degree of } \\
\text { nausea or vomiting in patients in the dying process. }\end{array}$ & $\mathrm{C}$ & \\
\hline
\end{tabular}

Recommendation 10. Evaluation of Pain

\begin{tabular}{lcc}
\hline & Evidence & Recommendation \\
\hline $\begin{array}{l}\text { We recommend that the pain of patients in the dying process should be regularly evaluated throughout the } \\
\text { dying process. }\end{array}$ & $\mathrm{D}$ & | \\
\hline
\end{tabular}

Recommendation 11. Pharmacological Treatment of Pain

\begin{tabular}{lcc}
\hline & Evidence & Recommendation \\
\hline $\begin{array}{l}\text { When patients in the dying process experience pain, immediate and proactive pain management by } \\
\text { selecting an effective medication should be considered. }\end{array}$ & $\mathrm{D}$ & $\| l a$ \\
\hline
\end{tabular}


improve after 24 hours of administration, octreotide can be considered. When nausea or vomiting is caused by opioids, a different type of opioid should be tried.

Pain should be regularly evaluated in every patient, including those who are unconscious. If the patient has difficulty describing his or her own level of pain (e.g., in patients with dementia or developmental problems), pain can be evaluated using specialized behavioral pain assessment tools. For dying patients in the critical care unit, the Critical Care Pain Observation Tool can be used to evaluate pain.

When patients in the dying process experience uncontrolled pain, opioids are given based on the level of pain, and the dose of the opioid should be controlled proactively. For patients dying due to deterioration of their diseases, an increased dosage of opioids may be required. This requirement should not be confused with tolerance, and the administration of pain medication should not be delayed. Oral administration should be considered first, and when necessary, the method of delivery (intraoral, intravenous, rectal, subcutaneous, sublingual, intramucosal, epidural, or intrathecal) may be adjusted after calculating the equivalent dose.

Clinicians should consider discontinuing medications that are not effective in symptom management or that can be harmful. Discussions with the patient and family members should precede any decision. When an adjustment of the administration method is necessary due to a change in the patient's status, the most effective method should be chosen based on whether the patient can safely swallow the medication and the patient's preferences.

The aim of administering sedative medication when death is near is to reduce consciousness or to induce unconsciousness in order to reduce severe pain. A systematic review of the literatures found that palliative sedation did not influence the length of survival among patients in the dying process [15]. Before palliative sedation is administered, it should be investigated whether all possible treatments have been conducted and whether decision-making or adjustment regarding the prognosis is necessary. When possible, patients themselves and their family members should be involved in the discussion of the reasons for and aims of palliative sedation. The patient's

Recommendation 12. Planning of Medication Use

\begin{tabular}{lcc}
\hline & Evidence & Recommendation \\
\hline $\begin{array}{l}\text { Medical staff should review the current medications taken by patients in the dying process and consider } \\
\text { discontinuing unnecessary medication. For medications taken for symptom management, changes in the } \\
\text { dose and method of administration should be considered according to changes in the patient's status. }\end{array}$ & $\mathrm{D}$ & $\|$ la \\
\hline
\end{tabular}

Recommendation 13. Palliative Sedation

\begin{tabular}{lcc}
\hline & Evidence & Recommendation \\
\hline For severe symptoms that do not improve with available treatments in patients in the dying process, & $\mathrm{D}$ & $\mathrm{llb}$ \\
palliative sedation may be considered. & & \\
\hline
\end{tabular}

Recommendation 14. Evaluation of Delirium

\begin{tabular}{lcc}
\hline & Evidence & Recommendation \\
\hline $\begin{array}{l}\text { When the psychological status or level of consciousness of patients in the dying process changes, } \\
\text { evaluation of delirium should be considered. }\end{array}$ & $\mathrm{D}$ & Ila \\
\hline
\end{tabular}

Recommendation 15. Non-Pharmacological Interventions for Delirium

\begin{tabular}{lcc}
\hline & Evidence & Recommendation \\
\hline $\begin{array}{l}\text { The use of physical restraints, indwelling catheters, and intravenous injections should be minimized in patients } \\
\text { in the process of dying who experience delirium, and non-pharmacological interventions, such as an adequate } \\
\text { explanation of any treatments and self-care, are recommended. }\end{array}$ & B & \\
\hline
\end{tabular}


religion, sociocultural preferences, current wishes, and goals of care should be considered.

Midazolam is most commonly used for sedation because its half-life and onset time are short, and sedation occurs proportionally to dosage. Otherwise, lorazepam or diazepam, which have a longer half-life, can be chosen as well.

Delirium is evaluated using the criteria in the Diagnostic and Statistical Manual of Mental Disorders-5. However, validated diagnostic tools for delirium have limited applicability in patients during the dying process, especially for patients with hypoactive delirium, a low level of consciousness, and impaired communication. The medical staff should review possible reversible causes of delirium such as pain, bladder or rectal bloating, metabolic disorders such as hyponatremia, and drugs (steroids, anticholinergics, narcotic analgesics, psychotropic drugs) and intervene accordingly.

Physical restraints should not be used in dying patients who experience delirium because they increase the risk of complications such as diminished function, cognitive decline, injury, suffocation, and death [11]. However, when patients pose a risk of physical injury for themselves and others or when pharmacological treatments have been tried without effect, physical restraints can be considered in exceptional cases when the potential benefit (safety) outweighs the potential risk (anxiety/increase in agitation). Even in such cases, the least limiting method should be used for the least amount of time.

Antipsychotics are first-line medications for the pharmacological management of delirium in patients in the dying process, except for delirium resulting from alcohol or benzodiazepine withdrawal. Generally, high-potency medications are preferred over low-potency medications. Haloperidol is recommended as a first-line medication. The starting dose of haloperidol is $0.5 \sim 2 \mathrm{mg}$ (subcutaneous or intramuscular), and the dose should be increased every 1 2 hours until symptoms improve. However, the patient should be observed since there is a risk of QT prolongation. In order to reduce the extrapyramidal side effects of haloperidol, atypical antipsychotic medications (risperidone, olanzapine, quetiapine) can be considered.

Reversible causes of anxiety or agitation (pain, bladder or

Recommendation 16. Pharmacological Treatment of Delirium

\begin{tabular}{lcc}
\hline & Evidence & Recommendation \\
\hline $\begin{array}{l}\text { Antipsychotics may be considered as the first-line pharmacological treatment for delirium in patients in the } \\
\text { dying process. }\end{array}$ & $\mathrm{B}$ & \\
\hline
\end{tabular}

Recommendation 17. Interventions for Anxiety or Agitation

\begin{tabular}{lcc}
\hline $\begin{array}{l}\text { Non-pharmacological or pharmacological interventions for anxiety or agitation are recommended in } \\
\text { patients in the dying process based on an assessment of the causes and history of anxiety disorders. }\end{array}$ & Evidence & Recommendation \\
\hline
\end{tabular}

Recommendation 18. Psychological Support (Communication with the Patient)

\begin{tabular}{lcc}
\hline & Evidence & Recommendation \\
\hline $\begin{array}{l}\text { In order to provide psychological and spiritual support for a sense of loss, lamentation, worry, and } \\
\text { fear, the medical staff should consider a holistic assessment that encompasses patients' physical, }\end{array}$ & $D$ & Ila \\
psychological, social, and spiritual condition. & \\
\hline
\end{tabular}

Recommendation 19. Effective Communication

\begin{tabular}{lcc}
\hline & Evidence & Recommendation \\
\hline $\begin{array}{l}\text { Medical staff should consider providing psychological and spiritual support to patients in the dying } \\
\text { process and their family members through appropriate and effective communication methods. }\end{array}$ & $D$ & $\| l a$ \\
\hline
\end{tabular}


rectal bloating, fever, electrolyte imbalance, drug use or withdrawal symptoms, unnecessary monitoring equipment), history of anxiety disorders, and spiritual issues should be evaluated comprehensively. Factors that interfere with peaceful death should be addressed by steps such as discontinuing unnecessary monitoring, turning off the alarms of the equipment, and adjusting the brightness of monitor screens. The medications in use should be evaluated regularly, and unnecessary medications should be discontinued. Benzodiazepines can be considered to address anxiety or anxiousness, and pain should be managed proactively. Throughout the dying process, sufficient explanations about future steps and support should be given.

As explanations and information about the treatment process are provided, clinicians should evaluate patients' and family members' internal distress caused by a sense of loss, mourning, lamentation, worry, and fear. Simultaneously, their values, meaning of illness, and religiosity, hope or inner strength should be understood. The appropriate spiritual or religious ceremonies after death and wishes of family members should be acknowledged.

The process through which medical staff establish trust and maintain an appropriate relationship with the patient and family is of the utmost importance. It is recommended that medical staff provide specific comments on the patient's emotions (e.g., "You look a bit sad today," "I know that the last few months must have been difficult for you"), use supportive phrasing ("My heart aches to hear that you had such a hard time; I hope we can try to improve your quality of life together"), and ask what patients are worried about most ("Can you tell me what worries you most at this moment?", "Which aspect is most difficult for you?", "In order for me to understand your situation better, can you tell me how you feel?") [4]. Medical staff should provide psychological and social support by having a compassionate attitude and trying to understand patients and their family members.

Shared decision-making is the process of establishing an individualized treatment plan by the patient, family, and the doctor considering what is most beneficial for the patient and which treatment best reflects the patient's values and preferences. For shared decision-making, the medical team should build trust by suggesting that patients and their family members should think about what the best option is together (team

Recommendation 20. Decision-Making (Communication among Patients, Family Members, and Medical Staff)

\begin{tabular}{lcc}
\hline & Evidence & Recommendation \\
\hline $\begin{array}{l}\text { To provide high-quality end-of-life care, shared decision-making with the patient, family members and } \\
\text { medical staff is recommended. }\end{array}$ & $\mathrm{C}$ & I \\
\hline
\end{tabular}

Recommendation 21. Advance Decision-Making

\begin{tabular}{lcc}
\hline & Evidence & Recommendation \\
\hline $\begin{array}{l}\text { We recommend that medical staff make advance decisions with patients in the dying process and their } \\
\text { family members as soon as possible. }\end{array}$ & $D$ & I \\
\hline
\end{tabular}

Recommendation 22. Sharing and Confirming Decisions

\begin{tabular}{lcc}
\hline & Evidence & Recommendation \\
\hline $\begin{array}{l}\text { We recommend that medical staff regularly check whether patients and family members have requests and } \\
\text { document them to share with the medical staff. }\end{array}$ & $\mathrm{D}$ & । \\
\hline
\end{tabular}

Recommendation 23. Evaluation of Family Care

\begin{tabular}{lcc}
\hline & Evidence & Recommendation \\
\hline $\begin{array}{l}\text { To provide care for family members of patients in the dying process, a comprehensive and holistic } \\
\text { assessment should be conducted. }\end{array}$ & $\mathrm{D}$ & lla \\
\hline
\end{tabular}


talk), explain the expected benefits and risks of treatment methods applicable to the patients (option talk), and help with making an appropriate decision (decision talk).

In order to provide high quality end-of-life care, the medical staff should first form a consensus about prognosis and treatment methods and explain the plan to patients and family members when everyone is present. The medical staff should seek appropriate timing for advance decisions so that discussions can take place when the situation is not urgent.

The decision-making process is influenced by factors such as the communication skills of medical staff, clinical experience, relationships with patients, and disagreements among family members. When a care plan is established regarding the prognosis of patients in the dying process, the medical staff should document the plan clearly. The documentation is not limited to advance directives. The patient's wishes about end-of-life care (e.g., location of death) should be applicable regardless of the type of medical institution; therefore, the results of the decision-making process should be documented and shared with the medical staffs.

The medical staff should understand the strengths and limitations of the family, such as resilience, sociocultural support system, the effects of diseases, prior experiences of disease and loss, drug abuse, neglect, and risk of abuse. The family' $s$ needs for care or support should be understood considering their education, occupation, hobbies, and economic activities, as well as changes of family members. The patient's and family's capacity of care, such as as using appropriate equipment, changing the home structure, or transportation, should be evaluated. Resources in the community, financial support, and needs for rest should also be considered. Through a comprehensive and holistic evaluation, medical staff should strive to

Recommendation 24. Provision of Individualized Family Care

\begin{tabular}{lcc}
\hline & Evidence & Recommendation \\
\hline $\begin{array}{l}\text { Medical staff should evaluate the risk factors for complicated grief in family members and consider providing } \\
\text { services for the family members (including caregivers). }\end{array}$ & $D$ & $\| l a$ \\
\hline
\end{tabular}

Recommendation 25. Education for Patients and their Family Members

\begin{tabular}{lcc}
\hline & Evidence & Recommendation \\
\hline $\begin{array}{l}\text { Medical staff should provide information about end-of-life care to patients in the dying process and their family } \\
\text { members and should consider checking whether they understand that information. }\end{array}$ & $\mathrm{D}$ & $\| l a$ \\
\hline
\end{tabular}

Recommendation 26. Roles of the Team Members (Communication among Members of the Medical Team)

\begin{tabular}{lcc}
\hline & Evidence & Recommendation \\
\hline In order to provide patient-centered end-of-life care, it is recommended to form a multidisciplinary team & $\mathrm{C}$ & \\
that consists of doctors, nurses, social workers, and others, and to communicate clearly and in a cooperative & & \\
manner.
\end{tabular}

Recommendation 27. Education of Medical Staff

\begin{tabular}{|c|c|c|}
\hline & Evidence & Recommendation \\
\hline Professional training for medical staff who care for patients in the dying process is recommended. & $\mathrm{D}$ & । \\
\hline \multicolumn{3}{|l|}{ Recommendation 28. Medical Team Care } \\
\hline & Evidence & Recommendation \\
\hline $\begin{array}{l}\text { Medical institutions, in order to provide high quality end-of-life care, should proactively manage the health and } \\
\text { work satisfaction of the medical staff. }\end{array}$ & C & lla \\
\hline
\end{tabular}


understand the family structure and functions in order to plan for decision-making processes.

It is suggested to send condolence letters that contain information about grief support on a regular basis, but it may also be appropriate to consider connecting the family to organizations that specialize in grief and bereavement support.

Medical staff should provide information about possible changes in the dying process, including physical symptoms, to improve the coping ability of family members. It is especially important to inform patients and their family members about delirium, changes in consciousness, and changes in breathing.

When a multidisciplinary team is involved, the level of satisfaction of patients and family members increase, and it is beneficial for addressing grief. Communication among the team members should be cooperative and accurate. The role and responsibilities of each member should be clear. The team leader should emphasize horizontal communication within the team, and the team should debrief to identify problems and improve upon them.

Medical institutions should develop a training program that specifies the role of each member of the medical staff. In the dying process, decision-making involves the patient, family, and a multidisciplinary team, so the medical staff must be able to establish a preliminary assessment plan and have enough clinical knowledge to respond to unexpected situations effectively. Medical institutions should provide sufficient education for the staff to confirm deaths and provide a death declaration in an appropriate manner.

The distress of medical staff who experience loss of patients and mourning causes burnout, compassion fatigue, and moral pressure, which both affect the health of medical staff and can influence the care environment for patients. Leaders of the medical staff should confirm whether any team members cannot participate in carrying out advance directives due to personal beliefs or values, express respect for their opinions, and not burden them with participating in the implementation of advance directives. Medical institutions should manage team members at a high risk of burnout and create a work environment and culture where related issues can be improved.

\section{CONCLUSION}

Limited evidence reflects the differences in personnel and resources across medical institutions, but this guideline is meaningful in that it provides recommendations that reflect the realities of clinical practice in South Korea. This guidance was developed with doctors and nurses in general wards in mind, but it can be utilized in primary care settings, rehabilitation institutions (physical therapists) or institutions providing mental health care (counselors), and care hospitals or home care teams, as well as by medical staff who are caring for endof-life patients for the first time. It is also expected to be useful when there are conflicts in the decision-making process among patients, family, and medical staff. Shared decisionmaking (communication among patients, family members, and the medical staff) and team roles (in particular, education of medical staff) are important factors for providing end-of-life care to patients, and are also areas that require improvement. We hope that this guideline will be a step towards the ultimate aim of ameliorating pain in patients in the dying process, providing them with a holistic sense of peace, and allowing the dying process to be the completion of the patient's life.

\section{CONFLICT OF INTEREST}

No potential conflict of interest relevant to this article was reported.

\section{ORCID}

Jinyoung Shin, https://orcid.org/0000-0001-9558-1853

Yoon Jung Chang, https://orcid.org/0000-0001-7750-4213

So-Jung Park, https://orcid.org/0000-0002-5444-0250

Jin Young Choi, https://orcid.org/0000-0002-2138-3480

Sun-Hyun Kim, https://orcid.org/0000-0002-3221-3460

Youn Seon Choi, https://orcid.org/0000-0003-2406-5848

Nam Hee Kim, https://orcid.org/0000-0002-9381-0613

Ho-Kee Yum, https://orcid.org/0000-0002-7929-0906

Eun Mi Nam, https://orcid.org/0000-0003-0108-5352

Nayeon Moon, https://orcid.org/0000-0003-1578-4947

Jee Youn Moon, https://orcid.org/0000-0001-5551-7750

Hee-Taik Kang, https://orcid.org/0000-0001-8048-6247 
Jung Hun Kang, https://orcid.org/0000-0001-5013-2683

Jae-Min Park, https://orcid.org/0000-0001-8873-8832

Chung-Woo Lee, https://orcid.org/0000-0002-2851-2521

Seon-Young Kim, https://orcid.org/0000-0003-3185-9005

Eun Jeong Lee, https://orcid.org/0000-0002-0468-0766

Su-Jin Koh, https://orcid.org/0000-0002-1545-8036

Yonghwan Kim, https://orcid.org/0000-0002-9965-675X

Myongjin Agnes Cho, https://orcid.org/0000-0003-2511-

2909

Youhyun Song, https://orcid.org/0000-0001-5621-2107

Jae Yong Shim, https://orcid.org/0000-0002-9561-9230

\section{AUTHOR’S CONTRIBUTIONS}

Conceptualization: JYS, YJC, SJP, JYC, YSC, JYS. Data curation: JYS, NYM, HTK, JHK, JMP, CHL, YHK, YHS. Methodology: HTK. Supervision: YJC, SJP, JYC, YSC. Writing - original draft: JYS, SHK, NHK, EMN, MHP, NYM, JYM, HTK, JHK, JMP, CHL, SYK, EJL, SJK, YHK, MJC, YHS. Writing - review \& editing: HKY, JYS.

\section{SUPPLEMENTARY MATERIALS}

Supplementary materials can be found via https://doi. org/10.14475/kjhpc.2020.23.3.103.

\section{REFERENCES}

1. National Institute for Health and Care Excellence. Care of dying adults in the last days of life [Internet]. Care of dying adults in the last days of life (NICE); 2015 [cited 2018 Apr 17]. Available from: https://www.nice.org.uk/guidance/ng31.

2. Registered Nurses' Association of Ontario. End-of-life care during the last days and hours. Toronto, Ont:.Registered Nurses' Association of Ontario;2011.

3. National Consensus Project for Quality Palliative Care. Clinical practice guidelines for quality palliative care. 3rd ed. Pittsburgh:National Consensus Project for Quality Palliative Care;c2013.

4. American Society of Clinical Oncology. Patient-clinician communication. Alexandria, VA:American Society of Clinical Oncology (ASCO);2017.

5. Korean Society of Critical Care Medicine. Korean professional consensus for comfort care and withdrawing/withholding in the intensive care unit. Seoul:Korean Society of Critical Care Medicine (KSCCM);2018.

6. Agency for Healthcare Research and Quality. Palliative care for adults. Agency for Rockville, MD:Agency for Healthcare Research and Quality (AHRQ);2013.

7. Societe quebecoise des medecins de soins palliatifs (SQMSP) and the College des medecins du Quebec. Palliative sedation at the end of life. Montreal, Quebec:College des medecins du Quebec (CMQ);2016.

8. Australian Commission on Safety and Quality in Health Care. Essential elements for safe and high-quality end-of-life care. Sydney:ACSQHC;2015.

9. Druml C, Ballmer PE, Druml W, Oehmichen F, Shenkin A, Singer P, et al. ESPEN guideline on ethical aspects of artificial nutrition and hydration. Clin Nutr 2016;35:545-56.

10. McClave SA, DiBaise JK, Mullin GE, Martindale RG. ACG Clinical Guideline: Nutrition Therapy in the Adult Hospitalized Patient. Am J Gastroenterol 2016;111:315-34.

11. Canadian Coalition for Seniors' Mental Health. The assessment and treatment of delirium. Toronto, ON:Canadian Coalition for Seniors' Mental Health;2014.

12. Cherny NI, ESMO Guidelines Working Group. ESMO clinical practice guidelines for the management of refractory symptoms at the end of life and the use of palliative sedation. Ann Oncol 2014;25 Suppl 3:iii143-52.

13. National Comprehensive Cancer Network. NCCN clinical practice guidelines in oncology. Palliative care, Version 1. Fort Washington, PA:National Comprehensive Cancer Network:2018.

14. O'Driscoll BR, Howard LS, Earis J, Mak V. British Thoracic Society Guideline for oxygen use in adults in healthcare and emergency settings. BMJ Open Respir Res 2017;4:e000170.

15. Maltoni M, Scarpi E, Rosati M, Derni S, Fabbri L, Martini F, et al. Palliative sedation in end-of-life care and survival: a systematic review. J Clin Oncol 2012;30:1378-83. 
Supplementary Table 1. Levels of Evidence and Recommendations

\begin{tabular}{|c|c|c|}
\hline Evidence level & \multicolumn{2}{|l|}{ Definition } \\
\hline A & \multicolumn{2}{|c|}{$\begin{array}{l}\text { Evidence for the recommendation is clear (one or more randomized controlled trial, meta-analysis, or systematic literature } \\
\text { review) }\end{array}$} \\
\hline B & \multicolumn{2}{|c|}{$\begin{array}{l}\text { Evidence for the recommendation is trustworthy (one or more well-designed non-randomized clinical study, such as a case- } \\
\text { control or cohort study) }\end{array}$} \\
\hline $\mathrm{C}$ & \multicolumn{2}{|c|}{$\begin{array}{l}\text { Evidence for the recommendation exists, but is not trustworthy (low level of related evidence from observational studies or } \\
\text { case reports) }\end{array}$} \\
\hline $\mathrm{D}$ & \multicolumn{2}{|c|}{ Evidence for recommendation is based on expert opinions drawing upon clinical experience and expertise } \\
\hline Recommendation level & Definition & Phrasing of recommendation \\
\hline Class 1 & $\begin{array}{l}\text { The evidence level and benefits are clear, and the recommendation has } \\
\text { high utility in clinical practice. }\end{array}$ & Is recommended \\
\hline Class lla & $\begin{array}{l}\text { The evidence level and benefits are credible, and the recommendation } \\
\text { has high or medium utility in clinical practice. }\end{array}$ & Should be considered \\
\hline Class Ilb & $\begin{array}{l}\text { The evidence level and benefits are not credible, but the utility in clinical } \\
\text { practice is high or medium. }\end{array}$ & May be considered \\
\hline Class III & $\begin{array}{l}\text { The evidence level is not credible, the recommendation may cause } \\
\text { harm, and its utility in clinical practice is low. }\end{array}$ & Is not recommended \\
\hline
\end{tabular}

